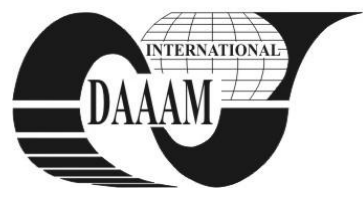

\title{
REDUCING THE ENVIRONMENTAL IMPACT OF TEXTILE DYES CONTAING WASTEWATER BY PHOTOCATALYTIC DEGRADATION WITH ZINCOXIDE NANOCOATED FIBERS
}

\author{
COMAN, D[iana]; VRINCEANU, N[arcisa] \& POPOVICI, E[veline]
}

\begin{abstract}
In textile wastewater, strong color is an important witch component and is very difficult to deal with. The experiments concerning color removal have been done by many researches using a variety of treatments like activated carbon, sodium hyperchloride or other chemicals as agents. Semiconductor photocatalytic oxidation of organic substances can be an alternative to conventional methods of removal of organic pollutants from water. In this research work, an attempt has been made to process to reduce the negative impact caused by pollutants from sewage factors of textile dyeing. There are presented aspects related to possible technological solutions discoloration of the water from the dyeing process with acid dyes (CI Acid Red 127) using zinc oxide nanocoated fibrous nanocomposites, as well as the wastewater management for minimizing the environmental impact in case of potentially polluting processes.The effectiveness of zinc oxide-mediated solar photocatalytic degradation of the acid dye and treatment of a textile dye wastewater were examined.
\end{abstract}

Key words: textiles, dyeing, pollution, wastewaters, photocatalysis, management

\section{INTRODUCTION}

Textile finishing sector is characterized by the use of large quantities of chemicals, textiles that are processed mainly in aqueous media, part of the industries with the largest quantities of waste water (Akyol, 2005).

Most of the chemicals used in textile wet finishing processes (dyeing, printing, final finishing) remain on textiles, but a significant amount of them are polluting the water sewage reaching or the aquatic ecological system.

The wastewaters reach the treatment tanks, being then directed to the purification or recycling plants (Coman, 2010).

The treatment and decolorouring of textile dye waste containing acid dyes by conventional chemical and biological methods is rather difficult. Semiconductor photocatalytic oxidation of organic substances can be an alternative to conventional methods of removal of organic pollutants from water. Some additional advantages of the photocatalytic process are noteworthy:

its mild operating conditions;

the activation of the semiconductor by sunlight (near UV), thus reducing significantly the electric power requirement and hence the operating cost.

Among the semiconductors, notably zinc oxide and titanium dioxide are known to be photosensitisers or photocatalysts (Joshi, 2006) These oxides are illuminated by photons having an energy level that exceeds their band gap energy excites electrons from the valence band to the conduction band and holes are produced in the valence band. In order to generate hydroxyl radicals which are strong oxidants, the photogenerated valence band holes react with either water or hydroxyl ions adsorbed on the catalyst surface. Titanium dioxide-mediated photocatalytic degradation of acid dye and decolourisation of textile dye waste containing acid dyes have been studied
(Kanmani, 2003; Reddy, 2005). Zinc oxide-mediated photocatalytic degradation of acid dye solutions have also been studied (Akyol, 2005). Taking into account this entire context, studying the effectiveness of zinc oxide as a photocatalyst for degradation of a certain acid dye, appeared very appropriate.

The present research was undertaken to examine zinc oxidenanocoated textile mediated UV photocatalytic degradation of a acid dye, CI Acid Red 127 and to clarify the most important aspects of reducing environmental impact using wastewater management.

\section{WASTEWATER MANAGEMENT FOR MINIMIZATION OF ENVIRONMENTAL IMPACT IN TEXTILE INDUSTRY}

The impact on textile wet activities on the environment led to measures of preventing and reducing the pollution quantity and quality, through sustainable management.

In order to evaluate the environmental impact generated by the environmental aspects identified in places where waterwaters interfere, all the characteristics of the resulted wastewaters, as well as the adequate evaluation criteria of the associated impacts should take into account.

In order to diminish the environmental impact of wastewater loading, a hierarchy of the pollutant concentration must be first established and then solutions for impact management proposed.

For effeciency environmental programs in the textile industry a few issues, of a great importance:

Wastewater prevention measures:

The possible measures for dimishing of wastewater and pollutant quantities are:

- The prevention of nocive substances at the selection of dyeing agents and textile agents in the manufacturing and finishing phase;

- The reusing of some retained and very concentrated wastes;

- The continuously reusage and usage of treated evacuated water;

- Some prevention measures at tearns and textile structures;

- Prevention measures at textile wet finishing.

Wastewater treatment measures

- Treatment at the wastewater source; Treatment before the mixing with the wastewater having another provenience; The final treatment of wastewater

Environment hazards of polutant factors from textile industry are: primary chemical agents for textiles (inorganic substances, aliphatic organic acids, reduction and oxidation organic agents, as well as urea); dyeing agents (dyes and pigments).

Due to the limited degree of fixation, relatively large quantities of dyes found in textile wastewater and in case of improper purges, the issue of staining watercourses occurs. In order to evaluate the environmental impact generated by the 
environmental aspects identified in places where wastewater interfere, all the characteristics of the resulted wastewaters, as well as the correct/appropriate/adequate evaluation criteria of the associated impacts should take into account.

The environmental impact of wastewaters could be decreased through a physico-chemical treatment of $80-85 \%$ and a biological treatment of $15-20 \%$ (Savin, 2009). An alternative to conventional methods of removal of organic pollutants from water is semiconductor photocatalytic oxidation of organic substances.

\section{EXPERIMENTAL ASPECTS}

Textile dye wastewater was obtained from an wellknown romanian textile company. .A acid dye used in textile dye printing, CI Acid Red 127, was obtained from the abovementioned textile company. The $\mathrm{ZnO}$ textile nano-coated were obtained in a previous research. For the research a fine-medium weight $100 \%$ linen woven fabric was used. In order to apply the nano-sized $\mathrm{ZnO}$ on the cellulosic fibrous support a 'pad-drycure' method was used. After padding, to polymerize the acrylic binder, the air-drying and subsequently curing for $3 \mathrm{~min}$ at 140 ${ }^{\circ} \mathrm{C}$ were performed. The fabric thus washed was air-dried. In order to make a comparison, one set of cellulosic fabrics was coated with bulk $\mathrm{ZnO}$.

Measuring the absorbance at the wavelength of maximum absorbance $(410 \mathrm{~nm})$ against a standard curve, the concentration of dye or colour of the dye waste was determined. A filtration of the dye waste was performed through a $0.45 \mu \mathrm{m}$ membrane filter before measuring the absorbance.

In order to perform zinc oxide nano-coated textiles-mediated UV photocatalytic degradation, some values of dye concentration were chosen: 20,50 and $100 \mathrm{mg} / \mathrm{l}$. One litre of the dye solution was taken in a 11 Pyrex beaker to which zinc oxide was added and kept in suspension by constant stirring and exposed to UV light. A $20 \mathrm{ml}$ aliquot was withdrawn at $30 \mathrm{~min}$ intervals, filtered through a $0.45 \mu \mathrm{m}$ membrane filter and the concentration of the dye in the filtrate was measured.

\section{RESULTS AND DISCUSSIONS}

Taking into account the previous researches, we assumed that preadsorption of substrate (organic substance) onto the photocatalyst is a prerequisite for highly efficient degradation. Previous researchers have used a dark adsorption period of 15$20 \mathrm{~min}$ before illumination for photocatalytic degradation of dyes to achieve sufficient solid-phase concentration of the substrate for preventing the recombination reaction. Before illuminating the semiconductor (zinc oxide)-dye suspension with UV light, in this study, 30 min dark adsorption was used. In figure 1, degradation of CI Acid Red 127 with varying zinc oxide dose (0.5-3.0 g/l) is shown. Increasing zinc oxide dose

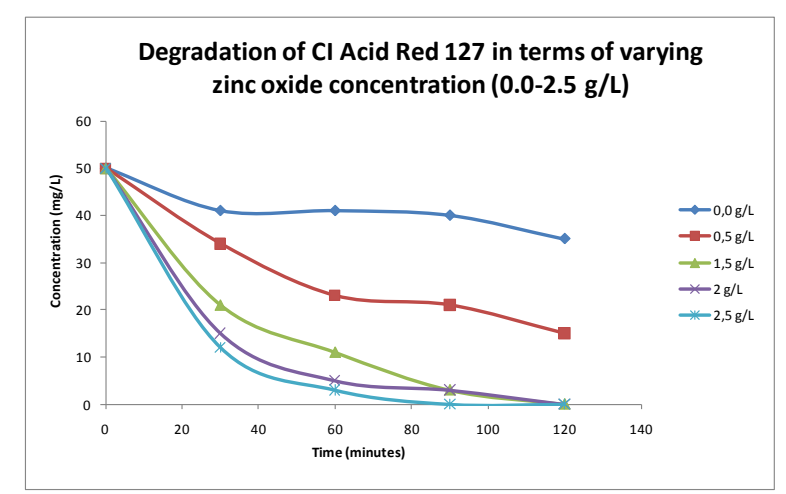

Fig. 1. Degradation of CI Acid Red 127 by varying zinc oxide dose from 2.0, 2.5 and $3.0 \mathrm{~g} / \mathrm{l}$, the maximum (98.10\%) dye degradation was achieved in $2 \mathrm{~h}$. A zinc oxide dose of $2.0 \mathrm{~g} / \mathrm{l}$ was chosen for degradation of CI Acid Red 127.

To ascertain whether dark adsorption of the dye onto the photocatalyst (zinc oxide) was a prerequisite for photocatalytic degradation, degradation of the dye after $30 \mathrm{~min}$ dark adsorption were studied (figure 2). No significant change in the rate of degradation and degradation $(99.88 \%$ and $99.86 \%$ ), respectively in $2 \mathrm{~h}$ was noticed. Hence, the pre-adsorption step was eliminated in all subsequent experiments.

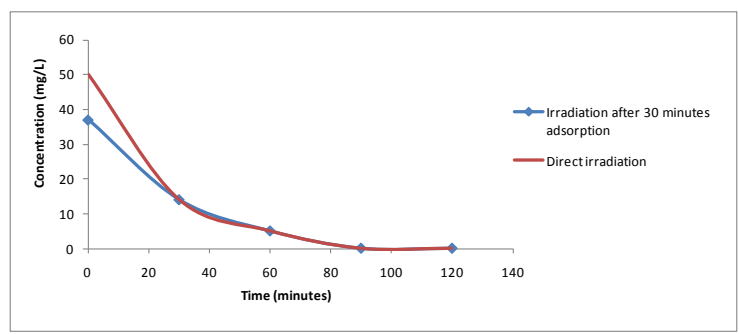

Fig. 2. Degradation of CI Acid Red 127 by direct illumination and by illumination after dark adsorption

\section{CONCLUSIONS}

Present study is an alternative solution and minimization the environmental impact of organic pollutants from wastewater with semiconductor photocatalytic oxidation.

Over $99 \%$ degradation of 20 and $50 \mathrm{mg} / \mathrm{l} \mathrm{CI}$ Acid Red 127 occurred by $2 \mathrm{~h}$ illumination under high UV light intensity and a zinc oxide dose of $2.0 \mathrm{~g} / \mathrm{l}$.

The method has demonstrated that photocatalytic oxidation mediated by zinc oxide-nano-coated textiles is effective in degradation of acid dyes and certainly to prevent the impact, or rather than reduce it.

Future research will focus on research on the use of other nanocoated composites fibers in the dyeing wastewaters, for reducing pollution risk, in fact an important goal for textile wastewater management.

\section{ACKNOWLEDGEMENTS}

The results of this research are partially due to the financially support of POSDRU/89/1.5/S/49944 Project, within European Structural Funds Framework.

\section{REFERENCES}

Akyol, A. \& Bayramoğlu, M. (2005). Photocatalytic degradation of Remazol Red F3B using ZnO catalyst, $J$. Haz. Mat., vol. 124, no.1-3, pp. 241-246, ISSN 0304-3894

Coman, D. \& Vrînceanu, N. (2010). Possibilities for monitoring and reducing of the environmental impact for industrial textile activities, Acta Universitatis Cibiniensis Tehnical series, vol.LX, pp.13-18, ISSN 1583-7149, Sibiu

Joshi, P., Purohit, J. \& Neti, N. R.(2006). Photocatalytic degradation of reactive dyes and simulated dyebath wastewater, J. Environ. Sci. Eng., vol. 48, no. 4

Kanmani, S. \& Thanasekaran, K. (2003). Decolourisation of industrial wastewaters of textile dyeing industry by photocatalysis, Ind. J. Chem. Tech., vol.10, no.1, pp. 53-59

Reddy, S. S. \& Kotaiah, B. (2005). Decolorization of simulated spent reactive dye bath using solar $/ \mathrm{TiO}_{2} / \mathrm{H}_{2} \mathrm{O}_{2}$, Int. J. Environ. Sci. Tech., vol. 2, no.3, pp. 245-252

Savin, I.I. \& Butnaru, R. (2009). Research on the treatment of wastewater in the textile industry, Environmental Engineering and Management Journal, vol.8., no.3, pp.589-593,ISSN1843-3707 